\title{
Venomous Snake Abundance Within Snake Species' Assemblages Worldwide
}

\author{
Luca Luiselli 1,2,3,*®D, Leonardo Sale ${ }^{4}$, Godfrey C. Akani ${ }^{1,2}$ and Giovanni Amori ${ }^{4}$ \\ 1 IDECC - Institute for Development, Ecology, Conservation and Cooperation, via G. Tomasi di Lampedusa 33, \\ 00144 Rome, Italy; gakanina2000@yahoo.com \\ 2 Department of Applied and Environmental Biology, Rivers State University of Science and Technology, \\ P.M.B. Port Harcourt 5080, Nigeria \\ 3 Department de Zoologie, University of Lomé, Lomé 01 BP 1515, Togo \\ 4 CNR - Research Institute on Terrestrial Ecosystems, viale dell'Università 32, 00185 Rome, Italy; \\ leonardosale@hotmail.com (L.S.); giovanni.amori@cnr.it (G.A.) \\ * Correspondence: 1.luiselli@ideccngo.org; Tel.: +39-06-99838517
}

Received: 30 December 2019; Accepted: 6 February 2020; Published: 7 February 2020

\begin{abstract}
Venomous snakes are among the main sources of mortality for humans in rural regions, especially in tropical countries. In this study, a meta-analysis of quantitative community ecology studies on snake assemblages throughout the world was conducted in order to evaluate variation in the frequency of occurrence of venomous species and venomous individuals by habitat and continent. A bibliographic search was done by consulting "Google Scholar" and "ISI Web of Knowledge". In total, 24,200 results were obtained from our bibliographic search, out of which 60 independent studies reporting raw and analyzable quantitative data from 81 distinct snake communities were retained and used for analyses. A snow-ball procedure was also used to uncover additional studies to include in the analyses. We gathered data on a total of 30,537 snake individuals, with an average of almost $30 \%$ of venomous individuals. The mean number of sympatric species was 19 , whereas the mean number of sympatric venomous species was almost 5 . Venomous snake species accounted for $24.4 \%$ of the total species in each community-almost the same as the overall percentage of venomous snake species known worldwide (about $24 \%$ ). The frequency of occurrence of venomous individuals did not differ significantly between tropical and temperate snake communities, and the same was true for the frequency of venomous species within each community. Thus, the greater number of snakebites in tropical countries is not due to there being more venomous snake species or individuals. The total number of species and the number of venomous species observed in each community were positively correlated, and there was a significant difference among continents in terms of the mean number of species in each community. Within communities, there were inter-continental and inter-habitat differences in both the percentage of venomous species and in the percentage of venomous individuals. The Generalized Linear Model (GLM) revealed that the frequency of venomous species at a local scale depended only on the total number of species inhabiting a given site, whereas the frequency of venomous individuals within communities depended on both the total number of species and a habitat-continent interaction. Our meta-analysis could enable the appropriate authorities/agencies to take the relative abundance of venomous species/individuals within snake assemblages into consideration for a better positioning of the first aid centers in locations where snake antivenoms should be available.
\end{abstract}

Keywords: reptilia; envenomation; meta-analysis; GLM; snakebite risk; community ecology 


\section{Introduction}

Venomous animals are an important cause of human mortality worldwide. According to the official database of the World Health Organization [1], there were about 5.4 million snake bites yearly (including also those from non-venomous species), with an annual range of 1.8-2.7 million cases of envenomation, 81,410-137,880 deaths, and approximately three times as many amputations and other permanent disabilities yearly. Thus, although the effect caused by a bite on human beings can depend on various circumstances (the toxicity of the species, the amount of venom injected, the age and physical condition of the affected subject, the region of the body affected and lastly the timeliness and the method of care used [1]), it is clear that the social and economic effect of snakebite epidemiology is relevant, particularly in rural areas of tropical countries [2]. Together with malaria and HIV-AIDS, venomous snakebite is among the leading causes of death in developing tropical countries [3]. South-East Asia is the region of the world with the highest number of cases of envenomations, due to its high human population density, widespread agricultural activities, and the presence of numerous highly venomous species including several species of cobra (genera Naja and Ophiophagus), kraits (genus Bungarus) and vipers (for example, genera Daboia and Trimeresurus) [2]. Despite the continuous increase of knowledge about the chemical properties of venoms and their actions and the clinical consequences of envenomations and the production of numerous antivenoms, the management of snakebite cases is still unsatisfactory in many regions of the globe, especially due to the lack of specific protocols $[2,3]$ but also to incomplete knowledge about the composition of snake assemblages [4,5]. In particular, variation in the abundance of venomous species and individuals in snake communities across habitats and biogeographic regions has not yet been explored.

In this study, we provide a meta-analysis of community ecology studies on snake assemblages throughout the world with emphasis on variation in the frequency of occurrence of venomous species and venomous individuals by habitat and continent. These data are potentially interesting in that they could theoretically be used to identify geographic areas and habitats with higher risk of snakebite. This is not trivial as it is well known that many envenomations are not reported in official datasets because, especially in remote areas of rural Africa, Asia and South America, bitten persons do not visit official hospitals but rely on traditional medicine practices [3]. As a consequence, the official snakebite data are heavily underestimated, and further research is urgently needed in this regard [6]. Although it can be estimated that the majority of bitten people in remote developing areas consult local doctors [3] (meaning they may not receive adequate treatment and may die without being even recorded in official data repositories), the high number of recorded snakebite cases may indicate a remarkable prevalence of venomous snake individuals, particularly in highly populated regions of Asia and Africa [6], but also a high human population density in rural areas. In fact, Australia certainly has the highest relative abundance of venomous snakes worldwide [7], yet it does not lead the world in snakebite cases, because Australia's human population density is very low compared to tropical Africa or Asia, and the infrastructure is good. Therefore, our present study would additionally contribute to the identification of neglected areas where snakebite events can represent a non-negligible threat to human beings.

\section{Materials and Methods}

We built the database by obtaining bibliographic data by consulting the search engine "Google Scholar" and "ISI Web of Knowledge", using the following keywords: "snake, community, assemblage".

We selected only articles reporting raw data and focusing explicitly on snakes. For each selected study, we considered the following:

(a) The total number of species present;

(b) The total number of venomous species present;

(c) The frequency of occurrence of individuals of venomous snakes in relation to the total observed. 
After the selection of the "quantitative studies" to be used for the analyses, we performed a snow-ball search for additional references by an examination of the literature cited in each of the selected studies. In addition, we also used a "snowball" search to identify key papers that have attempted to partially review snake assemblage studies (see Supplementary Materials). We considered both studies reporting data from only a single site or from multiple sites, but only if the description of the study areas was sufficiently precise to allow us to clearly define the list of species and the relative number of individuals at each examined site, as well as its habitat type and geographic coordinates.

Several studies provided checklists of species from single localities but did not quantify the relative frequency of occurrence (or raw number of individuals) for each species, and thus were not used in the present paper; other studies presented raw data but only for a subgroup of species (for instance, the semiaquatic species, or the viperid species) and were therefore excluded from our analyses.

We also included unpublished quantitative datasets (from Benin, Burkina Faso, Mali and Nigeria; see Table S1) that entirely fulfilled the requirements of the present meta-analysis.

We considered as "venomous" all species of vipers and elapids, including those that are not particularly or even at all dangerous to humans (e.g., Vipera ursinii complex, and members of the genera Azemiops, Causus, Ovophis in Viperidae, Aspidelaps, Cacophis, Denisonia, Furina, Brachyurophis, Antaioserpens, Neelaps, Echiopsis, Elapognathus, Hemiaspis, Suta, Cryptophis, Drysdalia, Ephalophis, Parasuta, Paroplocephalus, Rhinoplocephalus, Simoselaps, Vermicella, Aspidomorphus, Elapsoidea, Hemibungarus, Loveridgelaps, Ogmodon, Parapistocalamus, Salomonelaps, Sinomicrurus, Toxicocalamus in Elapidae) or those for which specific data on their venom and/or symptoms of their bites are still entirely absent. We excluded from the list of "venomous" species the entirely harmless seasnakes in the genera Emydocephalus and Aipysurus. We also considered as "venomous" atractaspid and colubrid snakes of the genera Atractaspis, Dispholidus and Thelotornis, as well as those genera with species that are strongly suspected to be dangerous for humans (Rhabdophis, Thrasops, Homoroselaps, Macrelaps). We excluded from the "venomous" category the many species of opisthoglyphous snakes that appear to vary in tooth morphology, "venom" gland morphology, and "venom" toxicity, and could be categorized as venomous in a biological sense without representing any threat to human life [8]. These genera would include Crotaphopeltis, Heterodon, Boiga, Hierophis, Platyceps, Leptodeira, Boiruna, Clelia, Hydrodynastes, Phalotris, Philodryas, Tachymenis, Natrix, Thamnophis, Psammophis, Malpolon, and many homalopsids.

We excluded from analyses all the studies that reported data on less than 30 individuals for a single site. This was necessary to avoid some species possibly being missed during the field studies, due to the elusiveness of many snake species. Unfortunately, given the type of raw data available in the various studies, it was impossible to build saturation curves to evaluate whether the field surveys were satisfactorily performed (with no new species being found at each site).

We also considered in each study the number of independent methods that were used to record snake species/individuals. We subdivided the various methods as follows: (a) random opportunistic search; (b) line-transects, other types of transects and time-constrained search; (c) roadkill; (d) trapping; (e) museum vouchers and other individuals stored in collections.

The correlation between the total number of species and the number of venomous species observed at each site was assessed using Pearson's correlation coefficient. The difference among continents in terms of the mean number of species in each community was tested by one-way ANOVA followed by Tukey Honestly Significant (HSD) post-hoc tests. One-way ANOVAs were also used to test for inter-continental and inter-habitat differences in both the frequency of venomous species and in the frequency of venomous individuals that were found within each selected snake community. The statistical difference between the observed frequency of venomous species within each community and the expected frequency of venomous snakes (determined as the frequency of venomous species among the total known, averaging $24 \%$ [7]) was assessed by using the $\chi^{2}$ test. We used the Mann-Whitney U-test to evaluate the statistical differences (i) in the frequencies of venomous species and (ii) in the frequencies of venomous individuals between tropical and temperate sites. We considered as "tropical" all the sites that were situated in-between the Tropic of Cancer in the Northern Hemisphere 
at $23^{\circ} 26^{\prime} 12.1^{\prime \prime}$ (or $23.43668^{\circ}$ ) N and the Tropic of Capricorn in the Southern Hemisphere at $23^{\circ} 26^{\prime} 12.1^{\prime \prime}$ (or $23.43668^{\circ}$ ) S.

We employed Generalized Linear Models (GLMs) to determine the relationship between the frequency of venomous snake species and frequency of venomous individuals by site, habitat type, and continent [9]. In the models, the "frequency of venomous snake species" and the "frequency of venomous individuals" were the dependent variables, and the identity of the link function and a normal distribution of error were used [10]. In the GLMs, the continent categories were Europe, Asia, Africa, Australia, North America and South America. We excluded Madagascar from our meta-analysis because there are no medically-important venomous snake species in that region; thus, including Madagascar in the analyses would have biased the estimates for the whole African continent. Habitat categories were: plantation/agriculture (PLANT), desert (DES), shrublands/savannas/grasslands (SHRUB), mangroves (MGR), rainforest (RFR), tropical forest (TRF), swamps/marshlands/lakes (SWM), and temperate forests (TEF). In the category "rainforest", only sites with an annual rainfall of 2500-4500 mm were included, whereas in the category "tropical forest", we included all the forest sites with less than $2500 \mathrm{~mm}$ annual rainfall. Rainfall data were obtained from the 2004 online dataset of the Food and Agriculture Organization of the United Nations-United Nations Environment Program.

In the GLM, we used a stepwise forward regression procedure to test the statistical significance of each variable in turn, and variables were excluded when they did not correlate significantly with the dependent variable (Wald test $P>0.05$ ). We used the identity of the link function and a normal distribution of error for our GLMs. The statistical software PASW 11.0 was used for all analyses, and alpha was set at $5 \%$. Means are presented followed by \pm 1 standard deviation (S.D.).

\section{Results}

Overall, we obtained a total of 24,200 results from our bibliographic search, but careful examination of the various articles resulted in a total of just 60 independent studies reporting raw and analyzable quantitative data from 81 distinct snake communities. Table S1 shows the data obtained from the studies that were used for the analyses. There were uneven frequencies of snake assemblages studied by continents: South American studies dominated in our sample $(n=29)$, followed by Africa $(n=18)$ and North America $(n=15)$ (see Table S1).

The selected studies reported a total of 30,537 individual snakes, with an average of $29.8 \pm 22.6 \%$ venomous individuals. The mean number of sympatric species was $19.3 \pm 11.2$ (range $=3-48$, median $=17$ ), whereas the mean number of sympatric venomous species was $4.8 \pm 3.1$ (range $=0-16$ ). Overall, venomous snake species accounted for $24.4 \%$ of the total species in each community; this frequency was not statistically different from the expected frequency (24\% of venomous species worldwide [7]; $\chi^{2}$ test with $\mathrm{df}=1, P=$ n.s.). The percentage of venomous individuals within each selected site did not differ significantly between tropical $(x=30.2 \pm 20.3 \%)$ and temperate regions $(29.0 \pm 26.7 \%)$ (Mann-Whitney U-test calculated on frequencies: $\mathrm{z}=-0.849, \mathrm{U}=595, P=0.396)$. The percentage of venomous species within each selected site did not differ significantly between tropical $(x=26.0 \pm 18.3 \%)$ and temperate regions $(20.8 \pm 21.2 \%$ ) (Mann-Whitney U-test calculated on frequencies: $\mathrm{z}=-1.531, \mathrm{U}=520, P=0.129$ ).

We found that studies using a combination of methods (e.g., pitfall, box traps, minnow traps, cover boards, visual encounter) detected (i) more species (correlation between number of methods employed per site and number of species: $r=0.447, P<0.05$ ) and (ii) more individuals (correlation between number of methods employed per site and number of observed individuals: $r=0.611, P<0.0001$ ) than studies using just one of these methods.

The percentage of venomous species was not correlated with the total number of individuals examined $(r=0.082, P=0.478)$. There was a significantly positive correlation between the total number of species and the number of venomous species observed in each community (Pearson correlation coefficient: $r=0.766, P<0.0001)$. In addition, there was a significant difference among continents in terms of the mean number of species in each community (Table 1; one-way ANOVA: $\mathrm{F}_{5,76}=10.35$, $P<0.0001)$. Tukey HSD post-hoc tests revealed that this statistical difference was due to Europe and 
Australia, where snake assemblages consisted of a significantly lower number of sympatric species than the other continents (Table 1).

Table 1. Synopsis of the number of species (and dispersion measures) of sympatric snakes among continents, on the basis of the selected studies.

\begin{tabular}{lcccccc}
\hline \multicolumn{1}{c}{ Statistics } & Africa & Asia & Australia & Europe & $\begin{array}{c}\text { North } \\
\text { America }\end{array}$ & $\begin{array}{c}\text { South } \\
\text { America }\end{array}$ \\
\hline Number of studies & 18 & 6 & 3 & 6 & 15 & 29 \\
Mean & 19.4 & 14.5 & 9.7 & 5.7 & 13 & 27.4 \\
Standard & 9.6 & 10.3 & 7.4 & 1.7 & 4.7 & 10.3 \\
deviation & 6 & 6 & 4 & 3 & 6 & 11 \\
Min & 45 & 34 & 18 & 8 & 20 & 48 \\
Max & & & & & \\
\hline
\end{tabular}

Venomous snakes accounted for a much higher fraction of sympatric species per site in Australia than in the other continents, with Africa placed second (Table 2). Within communities, there were statistically significant inter-continental differences in the frequency of venomous species (one-way ANOVA: $\mathrm{F}_{5,76}=25.14, P<0.0001$ ). Tukey HSD post-hoc tests revealed that the (i) frequency of venomous species was significantly higher in Australia than in all other continents (at least $P=0.00013$ ) in pairwise comparisons, and that (ii) the frequency of venomous species was also significantly higher in Africa than in all other continents apart from Australia (at least $P=0.0056$ ) in pairwise comparisons.

Table 2. Synopsis of the percentage (and dispersion measures) of venomous species within snake assemblages among continents, on the basis of the selected studies.

\begin{tabular}{lcccccc}
\hline \multicolumn{1}{c}{ Statistics } & Africa & Asia & Australia & Europe & $\begin{array}{c}\text { North } \\
\text { America }\end{array}$ & $\begin{array}{c}\text { South } \\
\text { America }\end{array}$ \\
\hline Number of studies & 18 & 6 & 3 & 6 & 15 & 29 \\
Min & 6.6 & 0 & 50 & 12.5 & 0 & 8.33 \\
Max & 61,5 & 50 & 85.7 & 33.3 & 36.3 & 36.3 \\
Mean & 39.6 & 18.7 & 71.2 & 19.5 & 14.6 & 15.7 \\
Standard deviarion & 12.2 & 21.3 & 18.8 & 7.4 & 10.7 & 5.8 \\
\hline
\end{tabular}

In terms of number of venomous individuals within snake communities (Table 3), Australian assemblages housed a much higher fraction than the other continents. Thus, the pattern mirrored that already observed for the number of venomous species in snake assemblages. Additionally, in this case, there were significant differences among continents in terms of frequency of venomous individuals (one-way ANOVA: $\mathrm{F}_{5,76}=5.78, P<0.001$ ), with Tukey HSD post-hoc tests showing that Australia significantly exceeded all other continents in pairwise comparisons (at least $P=0.0012$ ).

Table 3. Synopsis of the percentage (and dispersion measures) of venomous individuals within snake assemblages among continents, on the basis of the selected studies.

\begin{tabular}{lcccccc}
\hline \multicolumn{1}{c}{ Statistics } & Africa & Asia & Australia & Europe & N America & S America \\
\hline Number of studies & 18 & 6 & 3 & 6 & 15 & 29 \\
Min & 6.9 & 0 & 74.6 & 22 & 0 & 1.1 \\
Max & 70.4 & 58.2 & 91.7 & 49.4 & 62.0 & 71.5 \\
Mean & 38.3 & 22.3 & 81.5 & 29.4 & 24.1 & 23.7 \\
Standard deviation & 17.8 & 26.3 & 9.0 & 10.4 & 21.8 & 20.1 \\
\hline
\end{tabular}

There were significant differences in terms of the mean number of sympatric snake species across habitats (Table 4; one-way ANOVA: $F_{7,76}=4.06, P<0.01$ ), with Tukey HSD post-hoc tests highlighting that the highest statistical difference was between DES and RFR $(P=0.0095)$. Regarding inter-habitat 
differences in terms of frequency of venomous species within snake assemblages, mangroves housed a higher fraction of venomous species (Table 5). One-way ANOVA revealed that there were significant differences among habitats $\left(\mathrm{F}_{7,76}=3.59, P<0.01\right)$. In terms of the frequency of venomous individuals, the highest frequencies of venomous individuals were observed in MGR (Table 6), with significant differences across habitats (one-way ANOVA: $F_{7,76}=2.92, P<0.01$ ). More specifically, the Tukey HSD post-hoc test revealed that MGR had higher frequencies of sympatric venomous individuals than the snake communities from all the other habitats (at least $P=0.011$ ).

Table 4. Synopsis of the number of species (and dispersion measures) of sympatric snakes across habitats, on the basis of the selected studies. Abbreviations: MGR = mangrove; DES = desert; PLANT = plantation/agriculture; RFR = rainforest; SHRUB = shrublands/savannas/grasslands; $\mathrm{SWM}=$ swamps/marshlands/lakes; TEF $=$ temperate forest; $\mathrm{TRF}=$ tropical forest.

\begin{tabular}{lcccccccc}
\hline \multicolumn{1}{c}{ Statistics } & MGR & DES & PLANT & RFR & SHRUB & SWM & TEF & TRF \\
\hline Number of studies & 5 & 3 & 12 & 8 & 14 & 9 & 10 & 16 \\
Min & 13 & 7 & 4 & 6 & 3 & 6 & 5 & 11 \\
Max & 18 & 10 & 40 & 48 & 36 & 22 & 20 & 45 \\
Mean & 15.8 & 9 & 20.1 & 28.1 & 17.8 & 14.1 & 11.3 & 26.6 \\
Standard deviation & 1.8 & 1.7 & 10.8 & 14.7 & 11.3 & 5.4 & 5.2 & 10.8 \\
\hline
\end{tabular}

Table 5. Synopsis of the percentage (and dispersion measures) of venomous species within snake assemblages across habitats, on the basis of the selected studies.

\begin{tabular}{lcccccccc}
\hline \multicolumn{1}{c}{ Statistics } & MGR & DES & PLANT & RFR & SHRUB & SWM & TEF & TRF \\
\hline Number of studies & 5 & 3 & 12 & 8 & 14 & 9 & 10 & 16 \\
Min & 38.8 & 20 & 6.6 & 8.8 & 10.3 & 0 & 0 & 8.6 \\
Max & 61.5 & 42.9 & 77.8 & 50 & 85.7 & 25 & 27.3 & 44.4 \\
Mean & 50.1 & 30.9 & 33.7 & 26.5 & 23.9 & 11.4 & 12.6 & 22.3 \\
Standard deviation & 8.0 & 11.4 & 21.5 & 30.9 & 19.2 & 9.4 & 8.9 & 11.7 \\
\hline
\end{tabular}

Table 6. Synopsis of the percentage (and dispersion measures) of venomous individuals within snake assemblages across habitats, on the basis of the selected studies.

\begin{tabular}{lcccccccc}
\hline \multicolumn{1}{c}{ Statistics } & MGR & DES & PLANT & RFR & SHRUB & SWM & TEF & TRF \\
\hline Number of studies & 5 & 3 & 12 & 8 & 14 & 9 & 10 & 16 \\
Min & 39.5 & 6.9 & 3.1 & 5.4 & 1.1 & 0 & 0 & 4.0 \\
Max & 70.4 & 9.7 & 78.3 & 48 & 91.7 & 62.0 & 51.1 & 71.5 \\
Mean & 54.1 & 8.6 & 40.9 & 28.7 & 26.1 & 14.5 & 23.2 & 34.4 \\
Standard deviation & 11.0 & 1.5 & 24.6 & 14.9 & 24.0 & 22.5 & 18.7 & 20.8 \\
\hline
\end{tabular}

GLMs showed that the frequency of venomous species at a local scale depended only on the habitat type and the habitat-continent interaction (Table 7); similarly, the frequency of venomous individuals within communities depended on both the total number of species and the habitat-continent interaction, with MGR and Africa being the most positively influential factors on the abundance of venomous individuals (Table 8). 
Table 7. Results of the Generalized Linear Model (GLM) regarding the probability of an increase of the frequency of venomous species within snake communities in relation to the various factors analyzed in the present study. The significant effects are indicated in bold.

\begin{tabular}{|c|c|c|c|c|c|}
\hline Source & Type III Sum of Squares & df & Mean Square & F & $\mathbf{P}$ \\
\hline $\begin{array}{c}\text { Corrected } \\
\text { Model }\end{array}$ & 6385.93 & 3 & 2128.64 & 7.16 & 0.0001 \\
\hline Intercept & $21,711.23$ & 73 & 297.41 & 30.963 & 0.0001 \\
\hline $\begin{array}{c}\text { Total number } \\
\text { of species }\end{array}$ & 9289.67 & 32,44 & 289.68 & 0.68 & 0.874 \\
\hline Continent & 532.21 & 5,71 & 755.1 & 1.45 & 0.233 \\
\hline Habitat & 7500.69 & 7,69 & 1071.53 & 3.59 & 0.002 \\
\hline Habitat-continent & 890.973 & & 127.282 & 2.99 & 0.011 \\
\hline Error & $10,198.9$ & & 403.805 & & \\
\hline Total & $946,591.6$ & & & & \\
\hline Corrected Total & $66,623.200$ & & & & \\
\hline
\end{tabular}

Table 8. Results of GLM regarding the probability of an increase of the frequency of venomous individuals within snake communities in relation to the various factors analyzed in the present study. Symbol: MGR = mangrove. The significant effects are indicated in bold.

\begin{tabular}{|c|c|c|c|c|c|}
\hline Source & Type III Sum of Squares & df & $\begin{array}{l}\text { Mean } \\
\text { Square }\end{array}$ & $\mathbf{F}$ & Sig. \\
\hline Corrected Model & $37,315.00$ & 76 & 511.16 & 4.122 & 0.022 \\
\hline Intercept & 1421.80 & 1 & 182.08 & 41.223 & 0.000 \\
\hline Total number of species & 6511.2 & 50,26 & 644.51 & 2.57 & 0.02 \\
\hline $\begin{array}{l}\text { Total number of } \\
\text { Individuals }\end{array}$ & 146.167 & 1 & 146.167 & 0.351 & 0.559 \\
\hline Continent & $38,711.5$ & 5,71 & 516.15 & 0.05 & 0.825 \\
\hline Habitat & $29,877.5$ & 7,69 & 1264.2 & 2.92 & 0.010 \\
\hline $\begin{array}{c}\text { Total number of species } \\
\times \text { habitat }\end{array}$ & $37,882.9$ & & 840.328 & 2.63 & 0.014 \\
\hline $\begin{array}{l}\text { Habitat }\left(\mathrm{MGR}^{*}\right) \times \\
\text { continent }\left({ }^{*} \text { Africa) }\right.\end{array}$ & $48,112.3$ & & 855.3 & 2.71 & 0.012 \\
\hline Error & $10,410.3$ & & 436.2 & & \\
\hline Total & $345,999.2$ & & & & \\
\hline Corrected Total & $274,200.4$ & & & & \\
\hline
\end{tabular}

\section{Discussion}

We uncovered an uneven frequency of studies from the various continents, with South American studies dominating in the literature (e.g. [11]). This pattern was likely due to the fact the snake assemblages are more species-rich in tropical South America than elsewhere, thus making community ecology studies more interesting to carry out than in other geographic scenarios.

Our meta-analysis confirmed the general global biogeographic pattern that tropical snake communities are characterized by a higher number of species, and consequently also by a higher number of venomous species, than temperate snake communities [4]. These patterns were expected, given that (i) there is a well-known latitudinal increase of species richness towards lower latitudes (e.g., [12-14]), and (ii) the percent of venomous species observed within communities approached very closely the percentage of venomous species known worldwide [7]. The number of sympatric species varied considerably by habitat, with rainforests and tropical forests housing far more taxa than other habitat types. The high number of sympatric species certainly depend on (i) the multiple microniches (at different levels of height from ground) characterizing these habitats, and (ii) the fact that these habitats, despite occupying about $6 \%$ of the Earth's surface, house $40 \%-75 \%$ of all biotic taxa [15]. Since signals of interspecific competition, especially niche partitioning along the trophic dimension, are typically seen in snake assemblages [4], it can be predicted that interspecific competition 
should be particularly strong in species-rich microhabitats within rainforests and tropical forests. However, body size has no impact on competition or other factors that could potentially structure snake communities [16], whereas this character is known to greatly influence ecology and physiology for most organisms [17].

Importantly, we found that the frequency of both venomous species and venomous individuals was not statistically different between tropical and temperate sites. Thus, the fact that the great majority of snakebites worldwide occur in tropical areas is not a result of a higher frequency of venomous species within the snake assemblages, but rather is due to other factors (for instance, the higher number of people working in rural/forested areas or snakes are just more abundant in general nearby human settlements and therefore come into contact with people more often). Concerning this latter hypothesis, however, it should be considered that snake assemblage structure changes with anthropogenic changes to the landscape, particularly to agriculture, with some species becoming more common but many becoming rarer [18-20]]. In some cases, some venomous species (such as Bothrops asper or Naja nigricollis) will be positively impacted by agriculture, but in others, non-MIVS species (especially pythons like Python regius or Python reticulatus) appear to be the beneficiaries.

We also observed that there was a combined, positive effect of habitat-continent on the frequency of occurrence of venomous species within snake assemblages, with the highest number of encounters in African mangroves. This effect was mainly due to the sympatric presence of cobras (which often show affinity for water and frequently prey upon mudskippers [21]) and of arboreal ornithophagous venomous species (mainly Thelotornis and Dendroaspis) [22] that take advantage of the high densities of bird preys in mangroves. This may be important in terms of health risk, as there could be a high risk of being bitten by snakes in mangrove areas, particularly in the Niger Delta of southern Nigeria where the mangrove belt vegetation zone is among the largest in the world. Our unpublished data suggest that the number of snake bites is much higher in this habitat area than in the surrounding plantation/forest mosaic areas (Akani et al., unpublished data). Although our data are clear in this regard, it should be mentioned that our mangrove studies only come from Africa, with no mangrove snake study coming from any other continent. However, in the qualitative studies of mangrove snakes from other continents (these data do not mirror our criteria and thus could not be analyzed in the present paper), species checklists are mostly dominated by non-MIVS (see the Supplementary Materials for the list of these papers).

Our dataset also showed that there is a greater number of venomous species but fewer individuals in tropical forests and in rainforests than in the other habitat types. The higher venomous species richness in rainforests was expected as this type of vegetation typically hosts higher biodiversity $[15,23]$. The consequence is that, very likely, the risk of being bitten is not as high in the tropical forested areas as in the plantation/agriculture areas, where the number of sympatric venomous species is lower but the relative abundance of these species is higher. In this latter case, it is also obvious that the higher density of people at work may enhance the probability of an encounter with a venomous species.

Using the results obtained, it would be possible to draw an "empirical map" of the regions with the highest frequency of venomous species and individuals, divided by respective habitats. These areas are often characterized by the presence of high human density: for instance, the mangrove zone in southern Nigeria is among the economically most developed of the whole continent and has considerable human density. These rural populations are often in close contact with venomous snake assemblages, due to the activities they carry out (hunting and, above all, agriculture) [5]. These populations are often in a state of considerable poverty, such as in India, where mortality from snake bites is the highest in the world [23]. The Indian peninsula is populated by more than 60 species of highly venomous snakes, many of which are also abundant around human settlements. These species cause hundreds of thousands of bites and tens of thousands of deaths each year [24]. The most dangerous venomous species in this part of the world are the spectacled cobra (Naja naja), the banded krait (Bungarus caeruleus), the saw-scaled viper (Echis carinatus) and the Russell's viper (Daboia russelii) [25]. 
The correlation between the number of concurrent field methodologies used and the number of individuals and species detected per site clearly shows that, since snakes are difficult to detect, count data may not account for the imperfect detection of individuals [26-28]. This shortcoming should certainly be acknowledged when interpreting our results.

In conclusion, we would recommend taking into consideration the results of the present investigation, and especially the correlations of habitat with the presence and relative abundance of venomous species, when deciding to optimize the spatial positioning of first aid centers with snake anti-venoms available worldwide. We present the first global review of the relative abundance of venomous snake species and individuals within snake assemblages. Together with important factors such as human population density, dominant agricultural techniques and land use, accessibility to healthcare, and antivenom availability, data on the relative abundance of venomous snake species and individuals should be taken into account when estimating the relative risk of venomous snakebites. We also highlight that our meta-analysis did not cover papers focusing mainly on general reptilian groups and which did not focus specifically on snakes [29-35]. Thus, it is possible that adding these studies would slightly modify the observed patterns. However, we decided to avoid the inclusion of very general studies because snakes are much more elusive than most other reptiles (especially lizards), and thus the observed sample sizes in non-specifically dedicated snake studies may be biased towards few very common or non-elusive species.

Supplementary Materials: The following are available online at http://www.mdpi.com/1424-2818/12/2/69/s1, Table S1: Raw data on the snake communities analyzed during the present study. Numbers in brackets refer to citations given in the main text.

Author Contributions: Conceptualization, L.L. and G.A.; methodology, L.L., G.C.A., G.A.; software, L.L.; validation, G.C.A., G.A. and L.L.; formal analysis, L.L.; investigation, L.S.; resources, L.S.; data curation, L.S.; writing-original draft preparation, L.L. and G.A.; All authors have read and agreed to the published version of the manuscript.

Funding: This research received no external funding.

Acknowledgments: We are thankful to three anonymous referees that substantially improved the various drafts of the present manuscript.

Conflicts of Interest: The authors declare no conflict of interest.

\section{References}

1. World Health Organizations. Snakebite Envenoming, 2019. Available online: https://www.who.int/newsroom/fact-sheets/detail/snakebite-envenoming (accessed on 27 December 2019).

2. Alirol, E.; Sharma, S.K.; Bawaskar, H.S.; Kuch, U.; Chappuis, F. Snake Bite in South Asia: A Review. PLoS Negl. Trop. Dis. 2010, e603. [CrossRef] [PubMed]

3. Chippaux, J.-P. Snake Venoms and Envenomations; Krieger Publishing Company: Malabar, FL, USA, 2006.

4. Luiselli, L. Resource partitioning and interspecific competition in snakes: The search for general geographical and guild patterns. Oikos 2006, 114, 193-211. [CrossRef]

5. Akani, G.C.; Ebere, N.; Franco, D.; Eniang, E.A.; Petrozzi, F.; Politano, E.; Luiselli, L. Correlation between annual activity patterns of venomous snakes and rural people in the Niger Delta, southern Nigeria. J. Venom. Anim. Toxins incl. Trop. Dis. 2013, 19, 1-8. [CrossRef] [PubMed]

6. Chippaux, J.-P. Snake-bites: Appraisal of the global situation. Bull. World Health Organ. 1998, 76, 515-524.

7. Halliday, T.; Adler, K. The New Encyclopedia of Reptiles and Amphibians; Oxford University Press: Oxford, UK, 2002.

8. Weinstein, S.A.; Warrell, D.A.; White, J.; Keyler, D.E. Venomous" Bites from Non-Venomous Snakes: A Critical Analysis of Risk and Management of "Colubrid" Snake Bites; Elsevier: Amsterdam, The Netherlands, 2011.

9. Hosmer, D.W.; Lemeshow, S. Applied Logistic Regression Analysis, 2nd ed.; John Wiley and Sons: Hoboken, NJ, USA, 2000.

10. McCullagh, P.; Nelder, J.A. Generalized Linear Models; Chapman and Hall/CRC: London, UK, 1989.

11. Citeli, N.; Hamdan, B.; Guedes, T. Snake richness in urban forest fragments from Niterói and surroundings, state of Rio de Janeiro, southeastern Brazil. Biodivers. Data J. 2016, 4, e7145. 
12. Stevens, G.C. The latitudinal gradient in geographical range: How so many species coexist in the tropics. Am. Nat. 1989, 133, 240-256. [CrossRef]

13. Chown, S.L.; Gaston, K.J. Areas, cradles and museums: The latitudinal gradient in species richness. Trends Ecol. Evol. 2000, 15, 311-315. [CrossRef]

14. Mora, C.; Robertson, D.R. Causes of latitudinal gradients in species richness: A test with fishes of the Tropical Eastern Pacific. Ecology 2005, 86, 1771-1782. [CrossRef]

15. Golley, F.B. (Ed.) Tropical Rain Forest Ecosystems. Structure and Function. Ecosystems of the World, 14A ed.; Elsevier Scientific: Amsterdam, The Netherlands, 1989; pp. 29-47. ISBN 0-444-41986-1.

16. Burbrink, F.T.; Myers, E.A. Body size distributions at local, community or taxonomic scales do not predict the direction of trait-driven diversification in snakes in the United States. Glob. Ecol. Biogeogr. 2014, 23, 490-503. [CrossRef]

17. Blackburn, T.M.; Gaston, K.J. Animal body-size distributions-Patterns, mechanisms and implications. Trends Ecol. Evol. 1994, 9, 471-474. [CrossRef]

18. Hu, Y.; Magaton, S.; Gillespie, G.; Jessop, T.S. Small reptile community responses to rotational logging. Biol. Conserv. 2013, 166, 76-83. [CrossRef]

19. Gallmetzer, N.; Schulze, C.H. Impact of oil palm agriculture on understory amphibians and reptiles: A Mesoamerican perspective. Glob. Ecol. Biogeogr. 2015, 4, 95-109. [CrossRef]

20. Paoletti, A.; Darras, K.; Jayanto, H.; Grass, I.; Kusrini, M.; Tscharntke, T. Amphibian and reptile communities of upland and riparian sites across Indonesian oil palm, rubber and forest. Glob. Ecol. Biogeogr. 2018, 16, e00492. [CrossRef]

21. Luiselli, L.; Angelici, F.M.; Akani, G.C. Comparative feeding strategies and dietary plasticity of the sympatric cobras Naja melanoleuca and Naja nigricollis in three diverging Afrotropical habitats. Can. J. Zool. 2002, 80, 55-63. [CrossRef]

22. Luiselli, L.; Akani, G.C. An investigation into the composition, complexity and functioning of snake communities in the mangroves of south-eastern Nigeria. Afr. J. Ecol. 2002, 40, 220-227. [CrossRef]

23. Ghazoul, J.; Sheil, D. Tropical Rain Forest Ecology, Diversity, and Conservation; Oxford University Press: Oxford, UK, 2010.

24. Chippaux, J.-P. The treatment of snakebites: Analysis of requirements and assessment of therapeutic efficacy in tropical Africa. In Perspectives in Molecular Toxinology; Ménez, A., Ed.; John Wiley and Sons: Hoboken, NJ, USA, 2002; pp. 457-472.

25. Mohapatra, B.; Warrell, D.A.; Suraweera, W.; Bhatia, P.; Dhingra, N.; Jotkar, R.M.; Rodriguez, P.S.; Mishra, K.; Whittaker, R.; Jha, P. Snakebite Mortality in India: A Nationally Representative Mortality Survey. PLoS Negl. Trop. Dis. 2011; 5, e1018. [CrossRef]

26. Rodda, G.H. Where's Waldo (and the snakes)? Herpetol. Rev. 1993, 24, 44-45.

27. Steen, D.A. Snakes in the grass: Secretive natural histories defy both conventional and progressive statistics. Herpetol. Conserv. Biol. 2010, 5, 183-188.

28. Durso, A.M.; Seigel, R.A. A snake in the hand is worth 10,000 in the bush. J. Herpetol. 2015, 49, 503-506. [CrossRef]

29. How, R.; Dell, J. Reptile assemblage of the Abydos Plain, north-eastern Pilbara, Western Australia. J. R. Soc. West. Aust. 2004, 87, 85-93.

30. Luja, V.H.; Herrando-Pérez, S.; González-Solís, D.; Luiselli, L. Secondary rain forests are not havens for reptile species in tropical Mexico. Biotropica 2004, 40, 747-757. [CrossRef]

31. Brown, G.W.; Bennett, A.F.; Potts, J.M. Regional faunal decline-reptile occurrence in fragmented rural landscapes of south-eastern Australia. Wildl. Res. 2008, 35, 8-18. [CrossRef]

32. Hernández-Ordóñez, O.; Urbina-Cardona, N.; Martínez-Ramos, M. Recovery of amphibian and reptile assemblages during old-field succession of tropical rain forests. Biotropica 2015, 47, 377-388. [CrossRef]

33. Carpio, A.J.; Castro, J.; Mingo, V.; Tortosa, F.S. Herbaceous cover enhances the squamate reptile community in woody crops. J. Nat. Conserv. 2017, 37, 31-38. [CrossRef]

34. Ferreira, D.; Žagar, A.; Santos, X. Uncovering the rules of (reptile) species coexistence in transition zones between bioregions. Salamandra 2017, 53, 193-200. 
35. Ascano, C.P.; Albutra, Q.B.; Ansigbat, V.V.; Mugot, D.A.; Demayo, C.G. Reptile assemblage within and outside the hydraulicking mining area in Tumpagon, Cagayan de Oro City, Philippines. Adv. Environ. Biol. $2015,9,260-270$. 